\title{
Expanding the dynamic measurement range for polymeric nanoparticle $\mathrm{pH}$ sensors
}

\author{
Sun, Honghao; Almdal, Kristoffer; Andresen, Thomas Lars
}

Published in:

Chemical Communications

Link to article, DOI:

$10.1039 /$ c1cc10439j

Publication date:

2011

Document Version

Publisher's PDF, also known as Version of record

Link back to DTU Orbit

Citation (APA):

Sun, H., Almdal, K., \& Andresen, T. L. (2011). Expanding the dynamic measurement range for polymeric nanoparticle pH sensors. Chemical Communications, 47(18), 5268-5270. https://doi.org/10.1039/c1cc10439j

\section{General rights}

Copyright and moral rights for the publications made accessible in the public portal are retained by the authors and/or other copyright owners and it is a condition of accessing publications that users recognise and abide by the legal requirements associated with these rights.

- Users may download and print one copy of any publication from the public portal for the purpose of private study or research.

- You may not further distribute the material or use it for any profit-making activity or commercial gain

- You may freely distribute the URL identifying the publication in the public portal

If you believe that this document breaches copyright please contact us providing details, and we will remove access to the work immediately and investigate your claim. 


\title{
Expanding the dynamic measurement range for polymeric nanoparticle pH sensors $\dagger$
}

\author{
Honghao Sun, Kristoffer Almdal and Thomas L. Andresen* \\ Received 22nd January 2011, Accepted 15th March 2011 \\ DOI: $10.1039 / \mathrm{c} 1 \mathrm{cc} 10439 \mathrm{j}$
}

Conventional optical nanoparticle $\mathrm{pH}$ sensors that are designed for ratiometric measurements in cells have been based on utilizing one sensor fluorophore and one reference fluorophore in each nanoparticle, which results in a relatively narrow dynamic measurement range. This results in substantial challenges when conducting live cell measurements, which often leads to misleading results. In the present work we provide a simple solution to this problem.

A range of nanoparticle based sensors (nanosensors), based on optical detection using fluorophores, have been developed in recent years, ${ }^{1}$ and have valuable properties in comparison to methods using free dyes such as higher signal, a potential for controlled cellular uptake and low non-specific permeability through cellular membranes, possibility for ratiometric measurements and often higher dye photostability. ${ }^{1}$ Quantification of $\mathrm{H}^{+}$concentrations in intracellular compartments is highly important for understanding a number of cellular processes, e.g. the cell internalization pathways (the endosome-lysosome system) and transmembrane $\mathrm{H}^{+}$gradients in mitochondria, and furthermore has potential applications in tumor diagnostics, ${ }^{2-5}$ as well as a tool in development of new drug delivery systems. ${ }^{6,7}$

Nanoparticle $\mathrm{pH}$ sensors are particularly suited for measuring the $\mathrm{pH}$ in the endosome-lysosome pathway, where the $\mathrm{pH}$ ranges from $\sim 4.0$ to $\sim 7.4$, as nanoparticles are efficiently internalized by cells through endocytosis if they are designed correctly. As most commercially available fluorophores only have a sensitive range of up to $2 \mathrm{pH}$ units $\left(\mathrm{p} K_{\mathrm{a}} \pm 1\right.$, as a rule of thumb) they are not very suited for kinetic measurements in the endosome-lysosome pathway. A few $\mathrm{pH}$ sensitive fluorophores cover a broader $\mathrm{pH}$ range, such as pHrodo, but the fluorescence intensity of pHrodo does not change linearly with $\mathrm{pH}$ in the sensitivity range, which is problematic for microscopy based measurements.

We and others have earlier synthesized nanoparticle $\mathrm{pH}$ sensors that have the advantage of reducing fluorophore cytotoxicity and protein binding and interference, by coupling

Technical University of Denmark, Department for Micro- and Nanotechnology, DTU Nanotech, 2800 Lyngby, Denmark.

E-mail: thomas.andresen@nanotech.dtu.dk; Fax: +45 4588 7762;

Tel: +4545258168

$\dagger$ Electronic supplementary information (ESI) available. See DOI: $10.1039 / \mathrm{c} 1 \mathrm{cc} 10439 \mathrm{j}$ a $\mathrm{pH}$ sensitive fluorophore (e.g. fluorescein) and a $\mathrm{pH}$ insensitive dye (e.g. rhodamine $\mathrm{B}$ ) to a polymeric nanoparticle allowing ratiometric measurement of $\mathrm{pH}$ in living mammalian cells. ${ }^{8,9}$ When plotting the fluorescence intensity ratio $(R=$ fluorescein/ rhodamine) against $\mathrm{pH}$, we obtain a standard $\mathrm{pH}$ titration curve from which we can quantify the $\mathrm{pH}$ in an intracellular measurement without knowing the sensor concentration inside the cell. A sensor based on fluorescein can measure $\mathrm{pH}$ from $\sim 5.5$ to $\sim 7.3$ (fluorescein $\mathrm{p} K_{\mathrm{a}}=6.4$ ) and by changing the sensor fluorophore to Oregon Green 488 (Oregon) having a $\mathrm{p} K_{\mathrm{a}}=4.8$, we can change the measurement range to 3.9-5.7. ${ }^{8,9}$ However, when utilizing these sensors in cellular measurements in the endosome-lysosome pathway we have recently learned that the rather limited measurement range creates fundamental problems. The sensors will often encounter a $\mathrm{pH}$ that is at the limit of the detection range, which results in erroneous quantification of $\mathrm{pH}$ leaving such sensors practically unusable for measurements in living cells.

Fluorescein and Oregon have different $\mathrm{pH}$ sensitivity ranges, but have the same emission maximum $(520 \mathrm{~nm})$, which was envisaged to provide a possibility for expanding the measurement range of nanosensors by combining two or more $\mathrm{pH}$ sensitive fluorophores in the right ratio into a nanoparticle. The necessary ratio will depend on the quantum yield of the fluorophores at a specific $\mathrm{pH}$. We have investigated this possibility with the aim of developing a nanoparticle sensor that can measure $\mathrm{pH}$ in the entire range of the endosomelysosome pathway and have utilized a versatile synthetic strategy where multiple fluorophores are easily conjugated to the nanoparticles (NPs).

We aimed to synthesize polymeric NPs in the form of a hydrogel with free amines distributed in the network that act as functional groups for fluorophore attachment and in addition render the overall $\zeta$-potential of the particle positive. Positively charged particles are effectively endocytosed by cells. To achieve this, we first prepared the NP hydrogels as previously described. ${ }^{8}$ However, when preparing the nanosensors by reverse microemulsion polymerization using hexane and water, in the presence of dioctyl sodium sulfosuccinate (AOT) and with Brij30 as a co-surfactant, we found that even after 5 days of dialysis, the nanoparticles still had a negative $\zeta$-potential $(\sim-15 \mathrm{mV})$, which was due to AOT adhesion to the surface of the NPs. ${ }^{10}$ The negative surface charge results in poor cellular uptake of the nanoparticles and the AOT 

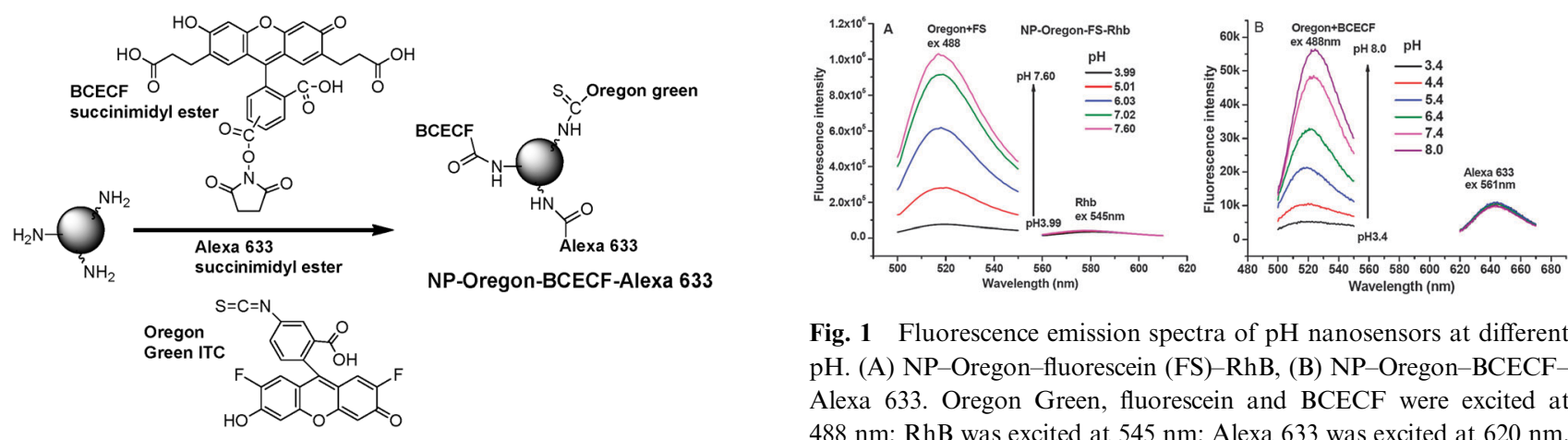

Fig. 1 Fluorescence emission spectra of $\mathrm{pH}$ nanosensors at different pH. (A) NP-Oregon-fluorescein (FS)-RhB, (B) NP-Oregon-BCECFAlexa 633. Oregon Green, fluorescein and BCECF were excited at $488 \mathrm{~nm}$; RhB was excited at $545 \mathrm{~nm}$; Alexa 633 was excited at $620 \mathrm{~nm}$.

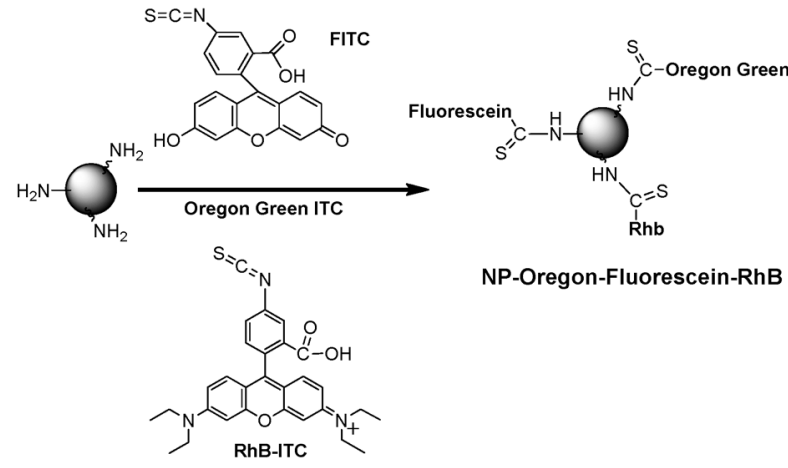

Scheme 1 Synthetic route for preparing $\mathrm{pH}$ nanosensors: NP-Oregonfluorescein-RhB and NP-Oregon-BCECF-Alexa 633.

influences further synthetic manipulation. To prevent this, we used the non-ionic surfactant TX-100 for preparing the NPs. ${ }^{11}$ The nanoparticles with free amines $\left(\mathrm{NP}-\mathrm{NH}_{2}\right)$ were prepared by copolymerization of acrylamide and bismethylacrylamide with 3-amino-propyl-acrylamide in a microemulsion (for experimental details see ESI $\dagger$ ).

To synthesize a nanosensor with three different fluorophores (see Scheme 1), to broaden the measurement range, it is crucial to adjust the ratio of two $\mathrm{pH}$ sensitive fluorophores, in this case Oregon and fluorescein. The accumulated fluorescence intensity of Oregon and fluorescein should preferably increase linearly in the $\mathrm{pH}$ range 3.9 to 7.3. As Oregon and fluorescein have approximately the same quantum yield, ${ }^{1}$ it is expected that the optimal molar ratio should be approximately $1: 1$.

The conjugation of the fluorescence dyes to the nanoparticles was easily achieved by a simple one-pot procedure using the commercially available isothiocyanates (ITC), i.e. FITC, Oregon Green ITC, RhB ITC that react readily with the free primary amine groups of the nanoparticles (Scheme 1). The reaction was carried out in a carbonate buffer solution at pH 9.2 for 1 hour at ambient temperature in the dark. The nanosensors were purified by dialysis against MilliQ water for 2 days. The success of the conjugation was verified by conducting a fluorescence emission scan using an excitation of $488 \mathrm{~nm}$ (Oregon and fluorescein) and $545 \mathrm{~nm}$ (RhoB) giving an emission maximum of $520 \mathrm{~nm}$ for fluorescein/Oregon and $580 \mathrm{~nm}$ for RhB (Fig. 1). The calibration curves of NP-Oregonfluorescein- $\mathrm{RhB}$ show an extended linear range at $\mathrm{pH} 3.9$ to 7.3 in comparison to the free dyes Oregon-RhB and fluorescein- $\mathrm{RhB}$ with a linear $\mathrm{pH}$ range of 3.9 to 5.7 and 5.8 to 7.3 , respectively (Fig. 2 and 3 ). This illustrates the

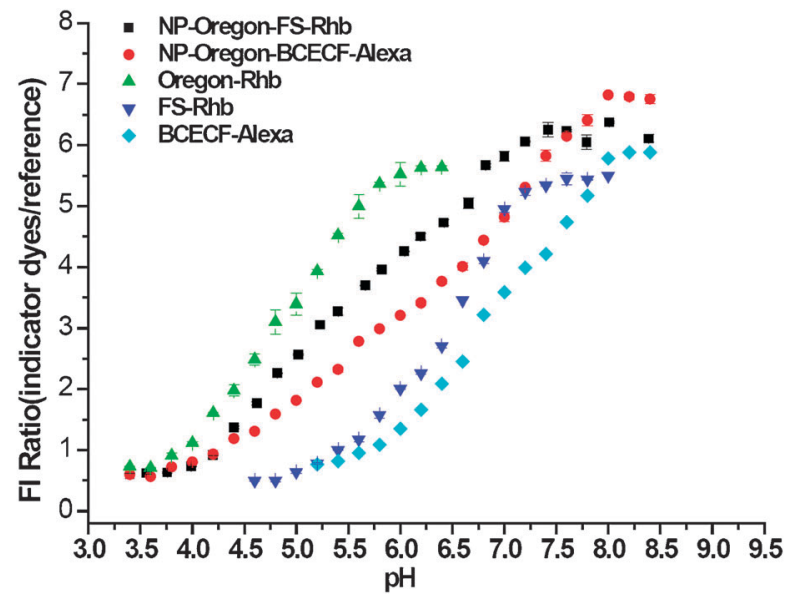

Fig. $2 \mathrm{pH}$ calibration curves of three free $\mathrm{pH}$ sensitive fluorophores Oregon/RhB, fluorescein (FS)/RhB, BCECF/Alexa 633, and two new pH sensing NPs, NP-Oregon-fluorescein (FS)-RhB, NP-OregonBCECF-Alexa 633. The fluorescence intensity ratio between $\mathrm{pH}$ sensitive fluorophores Oregon, fluorescein (FS), BCECF at $520 \mathrm{~nm}$ (excited at $488 \mathrm{~nm}$ ) and reference fluorophores $\mathrm{RhB}$ at $580 \mathrm{~nm}$ (excited at $545 \mathrm{~nm}$ ), Alexa 633 at $644 \mathrm{~nm}$ (excited $620 \mathrm{~nm}$ ) was plotted against $\mathrm{pH}$.

simplicity of the method for expanding the measurement range of nanoparticle sensors.

We have employed a post-conjugation method to bind the fluorophores. This method is much more efficient than our earlier reported method, ${ }^{8}$ where we synthesized acrylamidefluorophores that could be co-polymerized during the nanoparticle synthesis. We easily obtain 10 times higher concentrations of fluorophores in the nanoparticles, giving strong fluorescence intensity, which is important when conducting cellular measurements using microscopy.

The synthesized nanosensor NP-Oregon-fluorescein-RhB with a $\mathrm{pH}$ measurement range of $\mathrm{pH} 3.9$ to $\mathrm{pH} 7.3$ successfully serves the purpose of providing a sensor that can measure the $\mathrm{pH}$ in the endosome-lysosome pathway, with a minor limitation in the upper $\mathrm{pH}$ if one wants to measure e.g. the $\mathrm{pH}$ in the cytosol where the $\mathrm{pH}$ is expected to be 7.2-7.4. We have investigated how to enhance the $\mathrm{pH}$ measurement range further. One possibility is to add an additional sensor fluorophore with a high $\mathrm{p} K_{\mathrm{a}}$, but it would be more ideal if we could get away with only using two sensor fluorophores (and one reference).

2',7'-Bis-(2-carboxyethyl)-5-(and -6)-carboxyfluorescein (BCECF) with $\mathrm{p} K_{\mathrm{a}} 7.0$ has been used to measure neutral $\mathrm{pH}$ in cells and 
Free dye:Oregon pH 3.9-5.7

Free dye:Fluorescein $\mathrm{pH}$ 5.5-7.3

Free dye:BCECF pH 6.1-7.9

Nanosensor:NP-Oregon-Fluorescein-Rhb pH 3.9-7.3

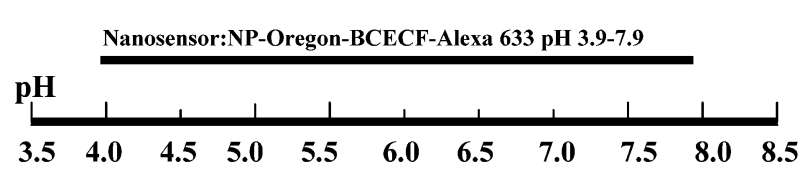

Fig. 3 The $\mathrm{pH}$ measurement range of individual free $\mathrm{pH}$ sensitive fluorophores Oregon, fluorescein, and BCECF and the polymeric nanosensors NP-Oregon-fluorescein-RhB, and NP-Oregon-BCECF-Alexa 633.
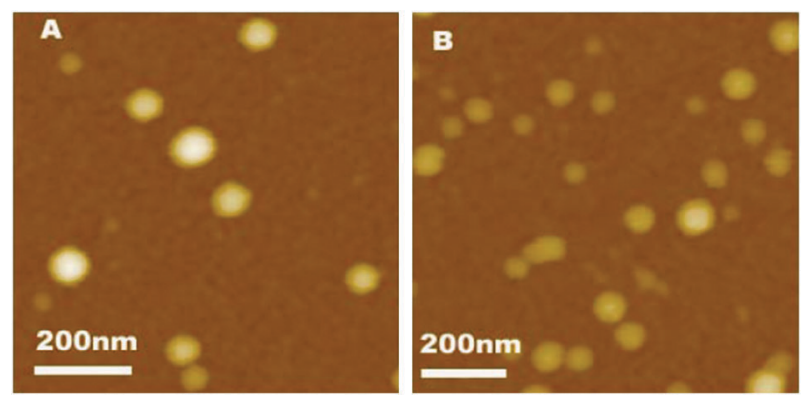

Fig. 4 AFM images of polymeric nanosensors; (A) NP-Oregonfluorescein-RhB, (B) NP-Oregon-BCECF-Alexa.

has been reported to have a linear increase of fluorescence intensity with $\mathrm{pH}$ between 6.1 and 7.9. ${ }^{12}$ If Oregon and BCECF were conjugated to nanoparticle sensors, the $\mathrm{pH}$ nanosensor could potentially measure in a broader measurement range. However, there was a risk that we could not obtain a linear ratiometric curve in the interval from 3.9 to 7.9 due to insufficient overlap in buffering capacity of the fluorophores in the region of $\mathrm{pH} 5.9$ ( $\mathrm{p} K_{\mathrm{a}}$ too far apart, Fig. 3). We found that a mole ratio of Oregon/BCECF $1: 1$, by titrating in the $\mathrm{pH}$ interval 3.9 to 7.9 , did not provide a sufficient linearity even though the quantum yields of the fluorophores are similar. ${ }^{1}$ We further found that the RhB concentration also affected the titration curve which could be attributed to weak Förster resonance energy transfer (FRET) between the sensor dyes and RhB. To avoid any further complications with FRET, we exchanged $\mathrm{RhB}$ with a fluorophore in the far red, Alexa $633,{ }^{13}$ with a maximum absorption at $\sim 633 \mathrm{~nm}$ and a emission maximum at $\sim 644 \mathrm{~nm}$, which was easily synthesized using succinimidyl esters to give a new nanosensor NP-Oregon-BCECF-Alexa 633 (Scheme 1). The nanosensor was titrated using standard $\mathrm{pH}$ adjusted buffer solutions and a plot of the fluorescence ratio $R$ ((Oregon + BCECF)/Alexa 633) vs. $\mathrm{pH}$ values is shown in Fig. 2. The titration curve showed a linear range between $\mathrm{pH} 3.9$ and 7.9, however, it is not quite as smooth as the sensor based on Oregon and fluorescein.
The $\zeta$-potential of these two new nanosensors NP-Oregonfluorescein-RhB and NP-Oregon-BCECF-Alexa 633 was measured in MilliQ water. The $\zeta$-potential of NP-Oregonfluorescein-RhB and NP-Oregon-BCECF-Alexa 633 was $13.4 \mathrm{mV}, 14.5 \mathrm{mV}$, respectively. Dynamic light scattering indicated that the hydrodynamic diameter of both nanosensors was $77 \mathrm{~nm}$. Atomic force microscopy indicated that the sensors have a spherical morphology and did not show any sign of aggregation (Fig. 4).

In conclusion, by labelling polyacrylamide nanoparticles with two $\mathrm{pH}$ sensitive fluorophores Oregon $\left(\mathrm{p} K_{\mathrm{a}}=4.8\right)$ and fluorescein ( $\mathrm{p} K_{\mathrm{a}}=6.4$ ), and the $\mathrm{pH}$ inert fluorophore $\mathrm{RhB}$, the nanosensor is capable of measuring a $\mathrm{pH}$ range from 3.9 to 7.3. To further expand the $\mathrm{pH}$ measurement range of the $\mathrm{pH}$ nanosensor, we developed another nanosensor containing two $\mathrm{pH}$ sensitive fluorophores Oregon and BCECF and the $\mathrm{pH}$ inert fluorophore Alexa 633. The new sensor with $\mathrm{pH}$ measurement range 3.9 to 7.9 could have great potential for measuring $\mathrm{pH}$ in almost all mammalian cellular environments. This method of labelling nanoparticles with two $\mathrm{pH}$ sensitive fluorophores can successfully expand the $\mathrm{pH}$ measurement range, to a range that is impossible to reach by using single fluorophores. This strategy offers a simple procedure for labeling nanoparticles with dual or multiple $\mathrm{pH}$ sensitive fluorophores to expand the $\mathrm{pH}$ measurement range and the method can be used in development of sensor technology for other metabolites.

The authors would like to thank Kræftens Bekæmpelse and the Danish Research Council for Technology and Production (Grant 274-07-0172) for financial support. Dr Barbara Windshiegl is gratefully acknowledged for her help with AFM.

\section{Notes and references}

1 J. Y. Han and K. Burgess, Chem. Rev., 2010, 110, 2709.

2 D. Peer, J. M. Karp, S. Hong, O. C. Farokhzad, R. Margalit and R. Langer, Nat. Nanotechnol., 2007, 2, 751.

3 J. Peng, X. X. He, K. M. Wang, W. H. Tan, Y. Wang and Y. Liu, Anal. Bioanal. Chem., 2007, 388, 645.

4 K. Na, E. S. Lee and Y. H. Bae, Bioconjugate Chem., 2007, 18, 1568.

5 D. S. Shenoy, S. Little, R. Langer and M. Amiji, Mol. Pharmacol., $2005,2,357$.

6 R. Duncan, Nat. Rev. Cancer, 2006, 6, 688.

7 T. L. Andresen, S. S. Jensen and K. Jørgensen, Prog. Lipid Res., 2005, 44, 68.

8 (a) H. Sun, A. M. Scharff-Poulsen, H. Gu and K. Almdal, Chem. Mater., 2006, 18, 3381; (b) H. H. Sun, T. L. Andresen, R. V. Benjaminsen and K. Almdal, J. Biomed. Nanotechnol., 2009, 5, 1 .

9 (a) S. M. Buck, H. Xu, M. Brasuel, M. A. Philbert and R. Kopelman, Talanta, 2004, 63, 41; (b) P. G. Coupland, S. J. Briddon and J. W. Aylott, Integr. Biol., 2009, 1, 318.

10 V. Holzapfel, A. Musyanovych, K. Landfester, M. R. Lorenz and V. Mailander, Macromol. Chem. Phys., 2005, 206, 2440.

11 K. McAllister, P. Sazani, M. Adam, M. J. Cho, M. Rubinstein, R. J. Samulski and J. M. DeSimone, J. Am. Chem. Soc., 2002, 124, 15198.

12 S. J. Lee, B. L. Ibey, G. L. Cot'e and M. V. Pishko, Sens. Actuators, B, 2008, 128, 388 .

13 R. P. Haugland, Handbook of Fluorescent Probes and Research Products, 2002, 9th edn, p. 20. 